\title{
LA-UR-19-31253
}

Approved for public release; distribution is unlimited.

Title: $\quad$ Production Facility Prototype Blower 1000 Hour Test Results IV

Author(s): $\quad$ Wass, Alexander Joseph

Woloshun, Keith Albert

Dale, Gregory E.

Romero, Frank Patrick

Dalmas, Dale Allen

Intended for: Report

Issued: 2019-11-06 
Disclaimer:

Los Alamos National Laboratory, an affirmative action/equal opportunity employer, is operated by Triad National Security, LLC for the National Nuclear Security Administration of U.S. Department of Energy under contract 89233218CNA000001. By approving this article, the publisher recognizes that the U.S. Government retains nonexclusive, royalty-free license to publish or reproduce the published form of this contribution, or to allow others to do so, for U.S. Government purposes. Los Alamos National Laboratory requests that the publisher identify this article as work performed under the auspices of the U.S. Department of Energy. Los Alamos National Laboratory strongly supports academic freedom and a researcher's right to publish; as an institution, however, the Laboratory does not endorse the viewpoint of a publication or guarantee its technical correctness. 


\section{Production Facility Prototype Blower 1000 Hour Test Results IV}

$9 / 30 / 2019$

Alexander Wass, Keith Woloshun, Greg Dale, Frank Romero, Dale Dalmas

\section{Introduction}

Long duration operations tests of the Aerzen GM 12.4 roots style blower in a closed loop configuration provides valuable data and lessons learned for long-term operation at the Mo-99 production facility. The blower was operated in a closed loop configuration with the flow conditions anticipated in plant operation with a Mo-100 target inline. The additional thermal energy generated from beam heating of the Mo-100 disks was not included in these tests. Twelve long duration 500 to 1000 hour tests have been completed since the first test was performed in January of 2016. All twelve long duration tests have proven successful in exposing preventable issues related to oil and helium leaks. All blower tests to this date have resulted in stable blower performance and consistency. A summary of the results for the end of the ninth test to the twelfth test is included in this report. Complete details for the previous tests are shown in the reports, Production Facility Prototype Blower 1000 Hour Test Results ${ }^{1}, \mathrm{II}^{2}$, and $\mathrm{II}^{3}$.

\section{Ninth Long Duration Operations Test - 1000 Hours}

The ninth long duration test with helium for 1000 hours was performed from 10/4/18 to $12 / 3 / 18$ which included weekly stoppages to simulate the periodic change-out of a target. The test section was changed out and the resistively heated target section was plumbed in to perform heated thermal tests. Therefore, the flow rate and blower RPM was lower than the prior long duration test.

The pressure vessel on the production prototype helium flow system was vacuumed down and pressurized with helium to $2068 \mathrm{kPa}$ (300 psig). The blower speed was set to $900 \mathrm{RPM}$ to achieve a high pressure drop that was below the torque limits of the blower. The blower torque was about $91 \mathrm{~N}-\mathrm{m}$, and the helium mass flow rate was $74 \mathrm{~g} / \mathrm{s}$ with a differential pressure of about $113 \mathrm{kPa}$ (16.4 psi). The rise in gas temperature through the blower was about $17^{\circ} \mathrm{C}$.

Upon completion of this test, the pressure vessel was depressurized, opened, and the blower was inspected for oil leaks. A slight oil leak was observed from the shaft seal and inlet check valve, as well as cloudy, dark oil in the shaft-side gearbox. LANL contacted the manufacturer (Aerzen) to help determine a diagnosis. The manufacturer suggested that grease and/or excessive heat can cause the oil to become darker. They requested to test an oil sample from the blower to test for overheated conditions. However, surface temperatures near the blower shaft seal never exceeded $50^{\circ} \mathrm{C}$, which did not seem excessive for the oil. The blower was sent to Aerzen for problem diagnosis and repair. It was determined that high pressure gas was likely being trapped inside the bearing/seal grease ports, thus, grease was being discharged from the seal into the gear oil, making it dark in color. Also, slight scoring on the bearing race and warn seals were found. Aerzen replaced all of the seals and bearings.

The blower was installed and aligned on 3/14/19. A bleed device was designed and fabricated for the bearing grease chamber to allow for pressure equalization with the vessel. The pressure vessel

\footnotetext{
${ }^{1}$ K. Woloshun, LA-UR-16-27971, Production Facility Prototype Blower 1000 Hour Test Results, 2016.

${ }^{2}$ A. Wass, LA-UR-18-20146, Production Facility Prototype Blower 1000 Hour Test Results II, 2018.

${ }^{3}$ A. Wass, LA-UR-18-29897, Production Facility Prototype Blower 1000 Hour Test Results III, 2018.
} 
was closed and torqued to $1200 \mathrm{lb}$-ft using the BLUE-GARD gasket in preparation for the tenth long duration test.

\section{Tenth Long Duration Operations Test - 880 Hours}

The tenth long duration test with helium for 880 hours was performed from $3 / 18 / 19$ to $4 / 23 / 19$ which included weekly stoppages to simulate the periodic change-out of a target. Just like the previous test, the resistively heated (Watlow) target test section was used to induce a pressure loss. The pressure vessel on the production prototype helium flow system was pressurized with helium to 2068 $\mathrm{kPa}$ (300 psig).

The blower speed was set to 900 RPM to achieve a high pressure drop that was below the torque limits of the blower. The blower torque was about $88 \mathrm{~N}-\mathrm{m}$, and the helium mass flow rate was $71 \mathrm{~g} / \mathrm{s}$ with a differential pressure of about $111 \mathrm{kPa}$ (16 psi). The rise in gas temperature through the blower was about $17^{\circ} \mathrm{C}$.

Upon completion of this test, the pressure vessel was depressurized, opened, and the blower was inspected for oil leaks. A thin layer of oil was seen on the blower and internal pressure vessel surfaces. It was determined that the oil had leaked out of the pressure relief system valve that was unintentionally left open prior to the start of this test. The valve and the pressure vessel were closed and torqued to $1200 \mathrm{lb}$-ft using the BLUE-GARD gasket in preparation for the eleventh long duration test.

\section{Eleventh Long Duration Operations Test - $\mathbf{5 0 0}$ Hours}

The eleventh long duration test with helium for 500 hours was performed from 4/25/19 to $5 / 22 / 19$ which included ten daily shutdown/restarts ( 5 minutes) to see if the $\sim 15$ psi pressure differential caused any additional oil leaks. The resistively heated (Watlow) target test section was replaced by a gate valve to achieve higher flow rates closer matching the production target design. The pressure vessel on the production prototype helium flow system was pressurized with helium to 2068 $\mathrm{kPa}$ (300 psig).

The blower speed was set to 1800 RPM to achieve a high pressure drop that was below the torque limits of the blower. The blower torque was about $93 \mathrm{~N}-\mathrm{m}$, and the helium mass flow rate was $280 \mathrm{~g} / \mathrm{s}$ with a differential pressure of about $101 \mathrm{kPa}$ (15 psi). The rise in gas temperature through the blower was about $9^{\circ} \mathrm{C}$.

Upon completion of this test, the pressure vessel was depressurized, opened, and the blower was inspected for oil leaks. A layer of oil was found on the blower surfaces, however, the oil level sight glass showed little to no oil loss. The origin of the oil was not clear, but speculated to be residual oil blown through the plumbing since this was the first test at high flow rates after the last oil leak. To assist in the diagnosis, we placed two GoPro Hero 7 White video cameras inside the pressure vessel on $7 / 24 / 19$ to help locate the origin of the oil. The cameras were accompanied with two $10,000 \mathrm{mAh}, 5 \mathrm{~V}$, $1 \mathrm{~A}$ battery banks to maintain a long battery life, as well as four Maglite XL250 200 lumen LED flashlights shown in Fig. 1. 


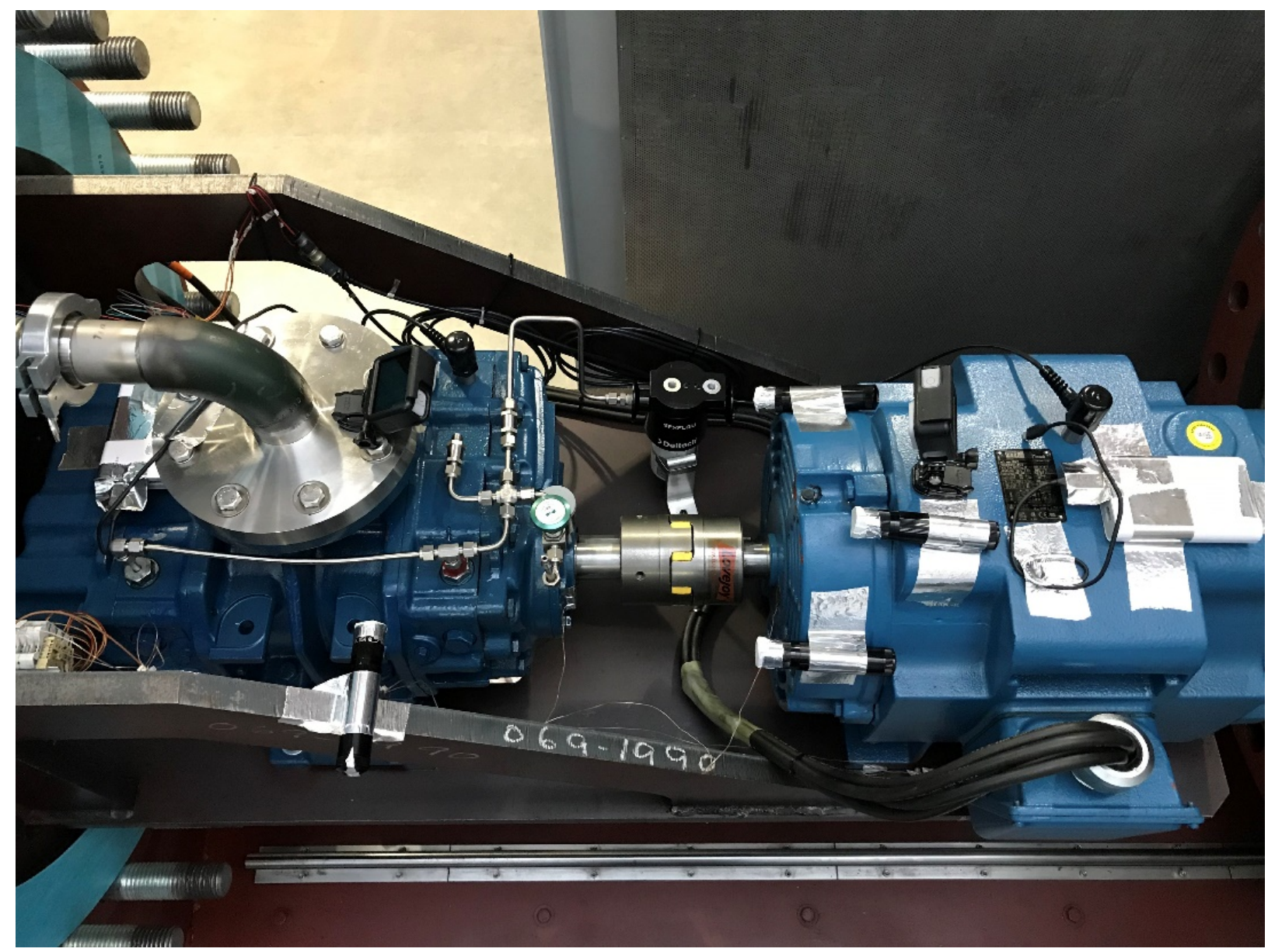

Figure 1 - Blower and motor with GoPro cameras, battery packs, and lights

Since the video time was limited by the flashlight battery life, the test had to be reduced to about four hours from close to open. The pressure vessel was closed, vacuumed, and pressurized with helium to 300 psig. The blower speed was increased in 300 RPM increments to 1800 RPM. Four restart cycles of ten minutes on and five minutes off were performed. The pressure vessel was then depressurized within $\sim 30$ minutes and opened. Only a small drop of oil was found and all other surfaces were completely dry. The origin of the drop of oil was not known. Fortunately, all lights were still on, and one camera was still recording. The second camera only recorded half the test duration before it succumbed to pressure damage. Figures 2-3 show still frames from the motor mounted camera when the pressure vessel was closed and opened, respectively. One can see that the lights had dimmed considerably, and the lens had become blurry due to the high pressure. Figure 4 shows a still frame from the second camera (located on top of the blower outlet flange) when the pressure vessel was closed. The pressure vessel was closed and torqued to $1300 \mathrm{lb}$-ft using the BLUE-GARD gasket in preparation for the twelfth long duration test. 


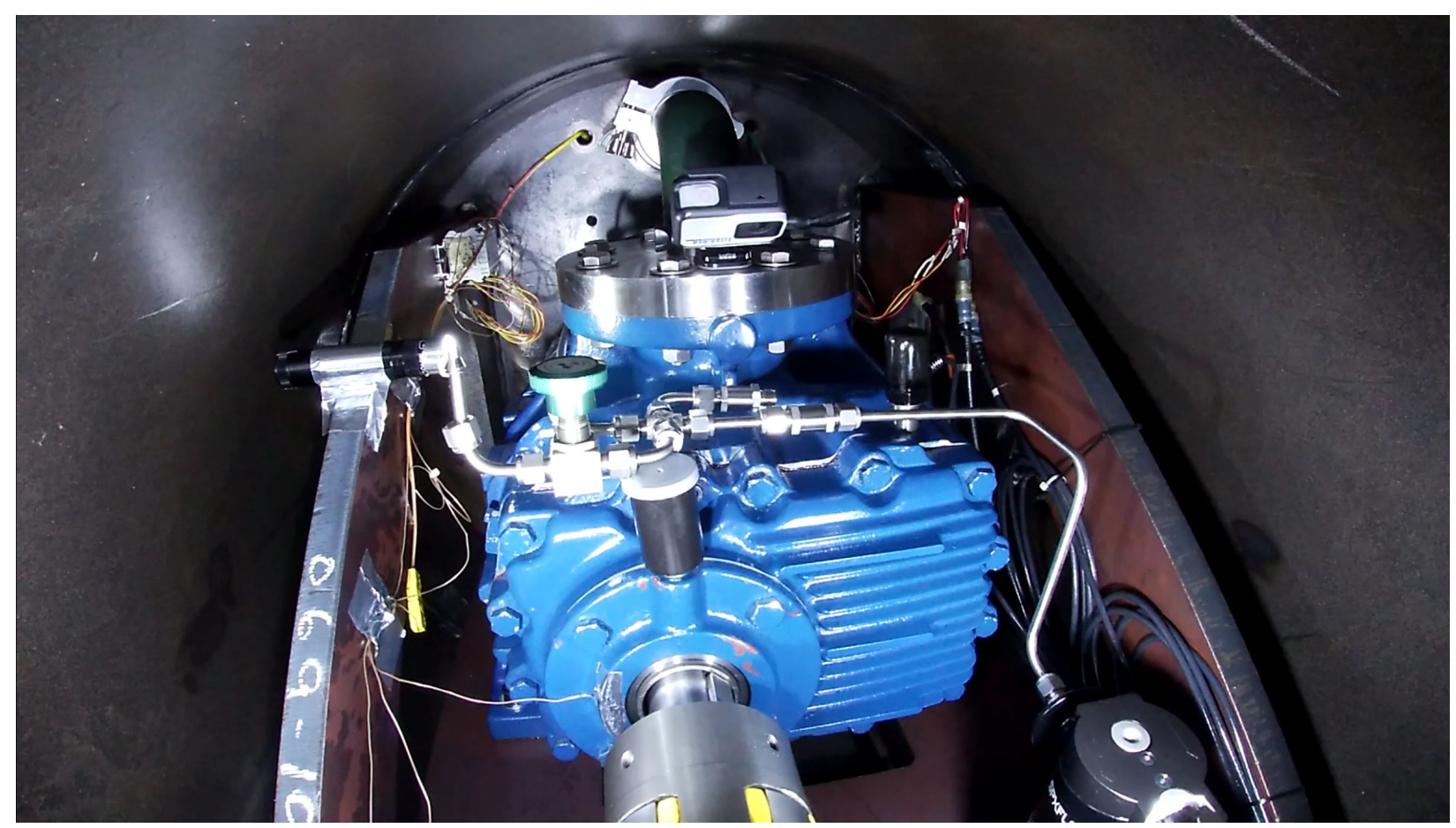

Figure $\mathbf{2}$ - Video camera \#1 still frame at initial close of pressure vessel

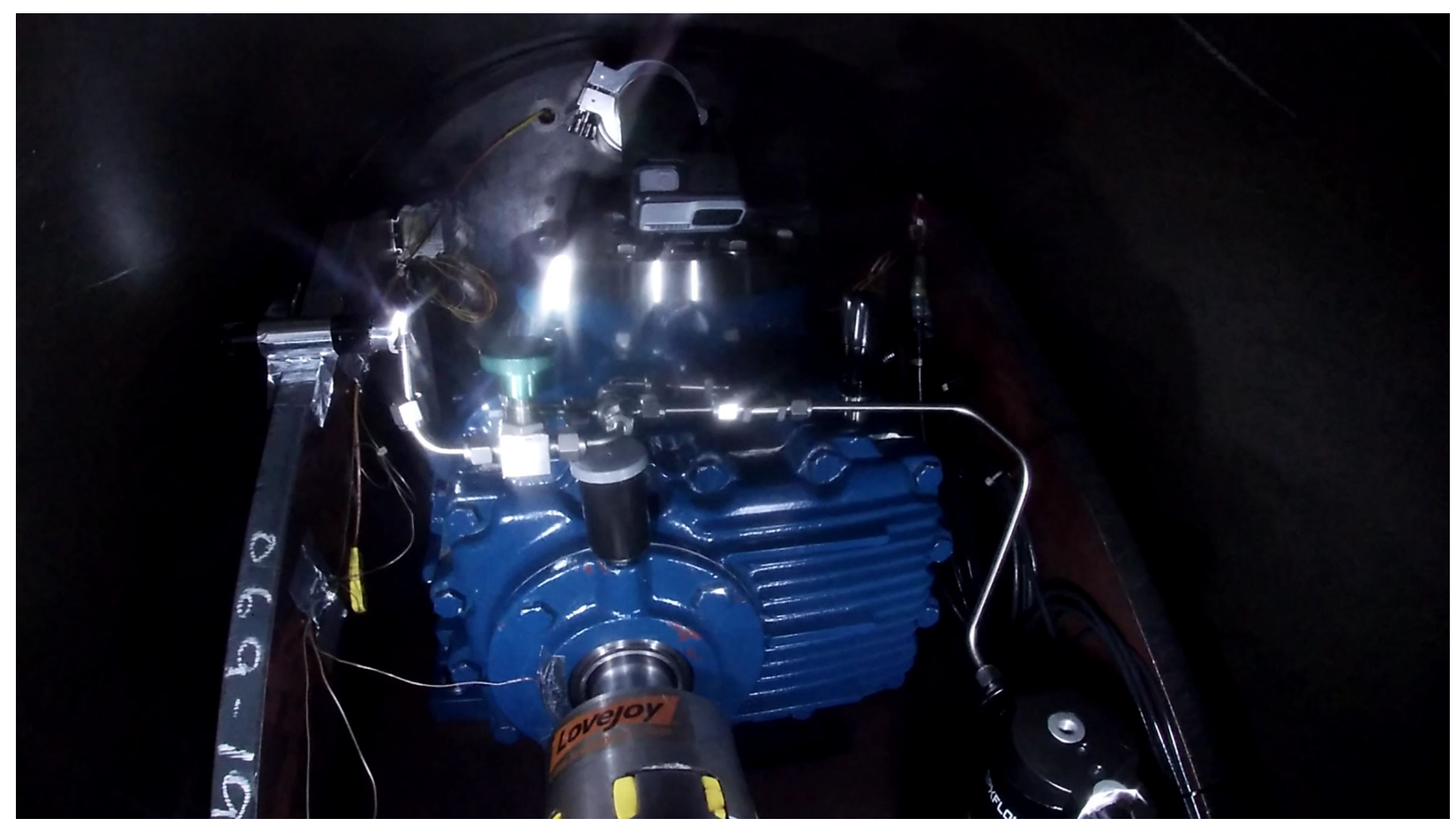

Figure 3 - Video camera \#1 still frame at end of test after 3 hours and 15 minutes 


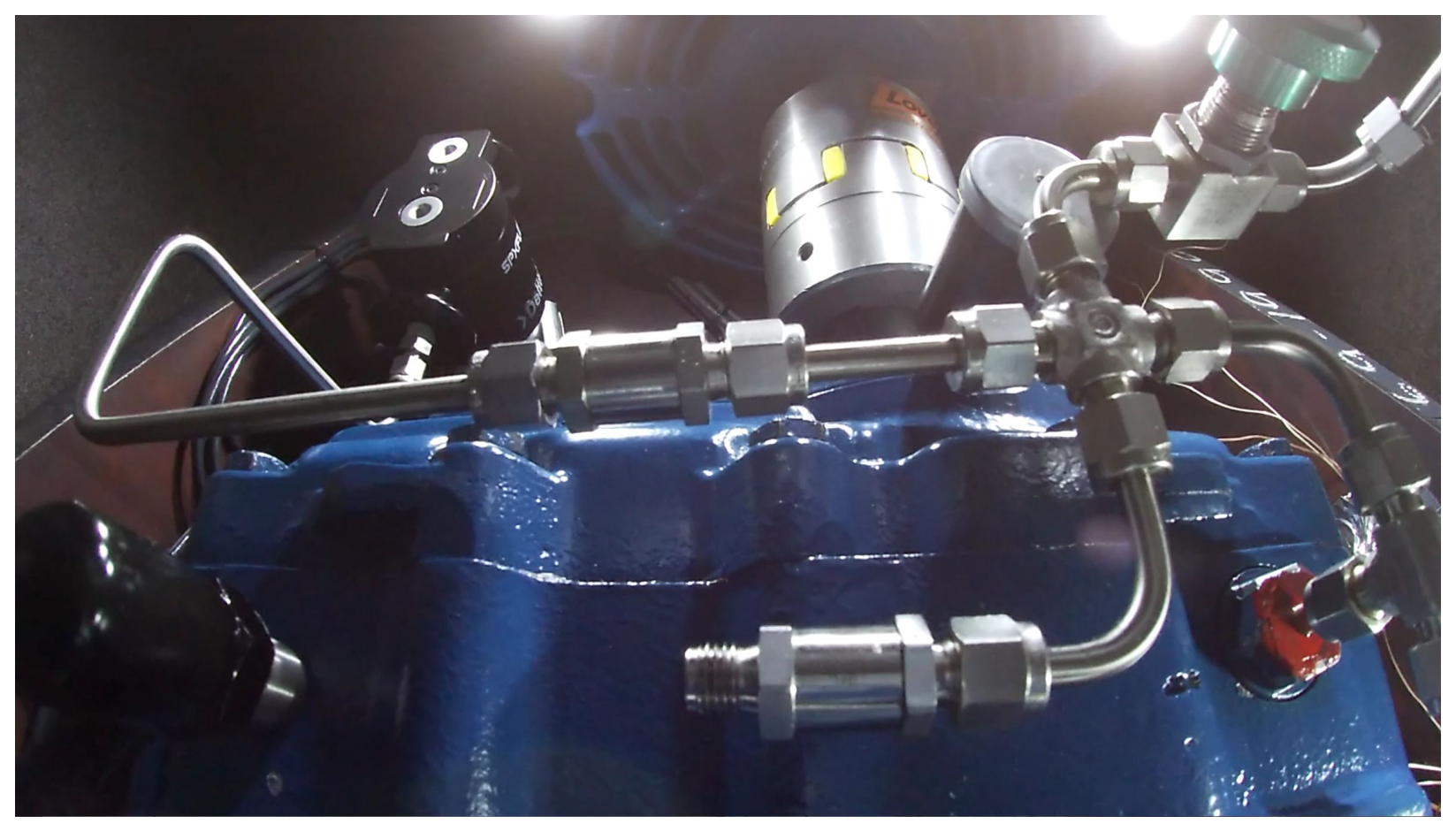

Figure 4 - Video camera \#2 still frame at initial close of pressure vessel

\section{Twelfth Long Duration Operations Test - 1000 Hours}

The twelfth long duration test with helium for 1000 hours was performed from 8/9/19 to $9 / 20 / 19$ which included daily shutdown/restarts ( $\sim 5$ minutes) to see if the $\sim 15$ psi pressure differential caused any additional oil leaks. The test section gate valve was used to achieve higher flow rates closer matching the production target design. The pressure vessel on the production prototype helium flow system was pressurized with helium to $2068 \mathrm{kPa}$ (300 psig).

The blower speed was set to 1800 RPM to achieve a high pressure drop that was below the torque limits of the blower. The blower torque was about $93 \mathrm{~N}-\mathrm{m}$, and the helium mass flow rate was $283 \mathrm{~g} / \mathrm{s}$ with a differential pressure of about $102 \mathrm{kPa}$ (15 psi). The rise in gas temperature through the blower was about $9^{\circ} \mathrm{C}$.

Upon completion of this test, the pressure vessel was depressurized slowly. The gas cylinder manifold was closed off and the helium naturally leaked out of the system for six days. The remaining helium was then released via valve for 3.5 hours (185 psig). Once depressurized, the vessel was opened, and the blower was inspected for oil leaks. Oil was found on the blower surfaces and localized around the shaft side gear box and pressure relief plumbing shown in Fig. 5 . The shaft side oil level had decreased since the beginning of the test, shown in Fig. 6 . The origin of the oil leak is unknown. 


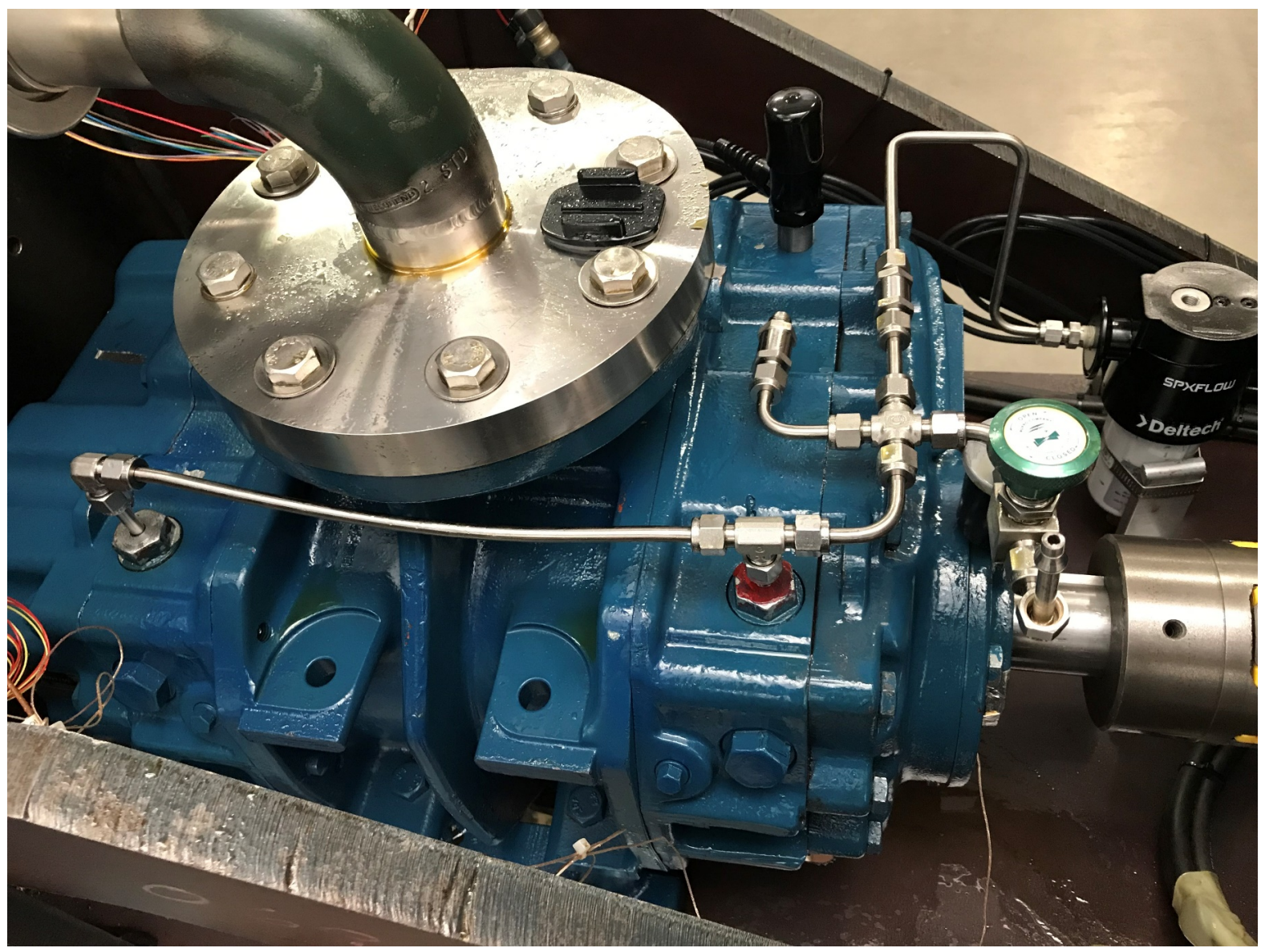

Figure 5-Oil on blower surfaces after twelfth test

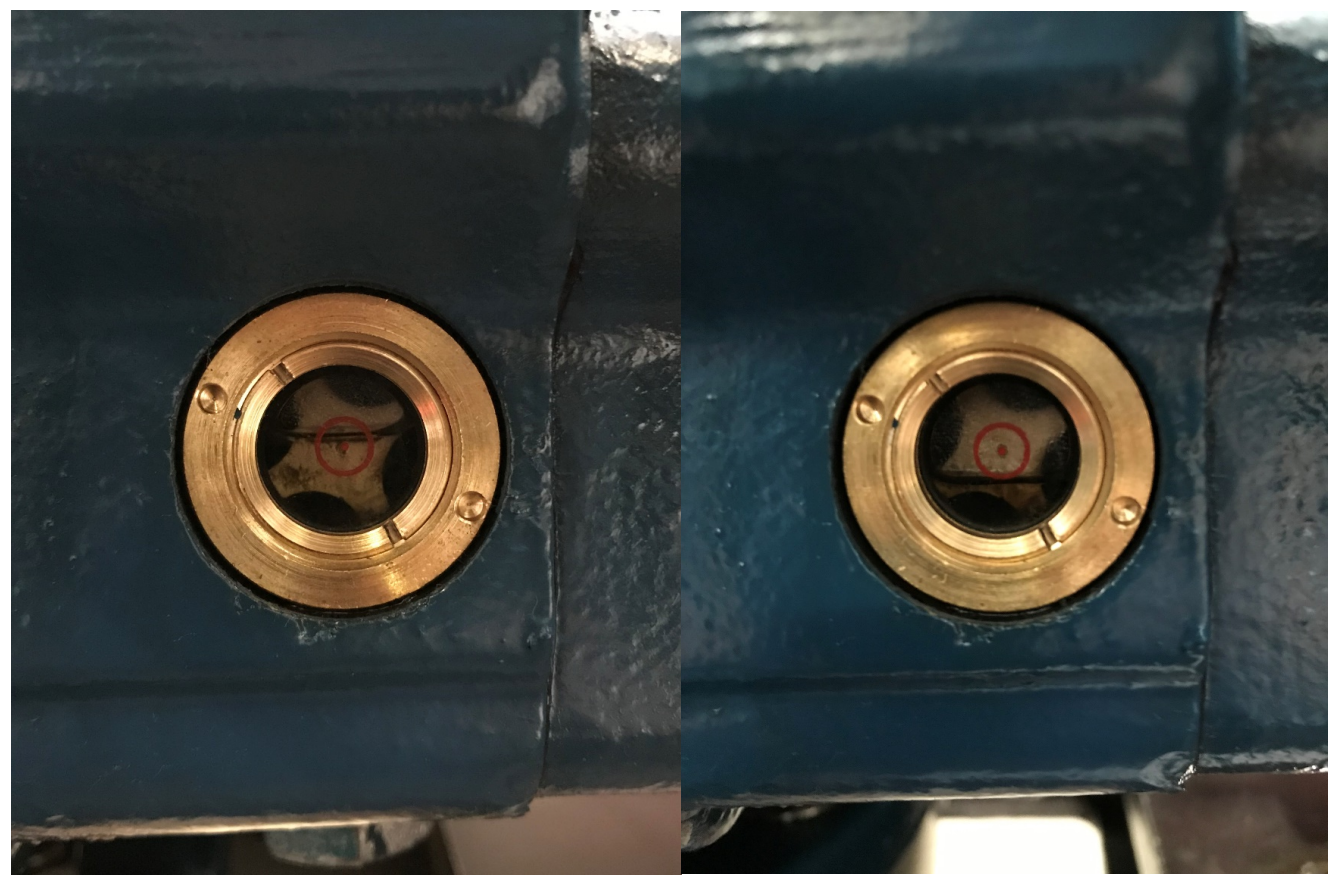

Figure 6 - Shaft side gearbox oil level before (left) and after (right) twelfth test 


\section{Conclusion}

The end of the ninth long duration test showed that grease had leaked (due to the pressure differential) in the shaft side gearbox, which caused darkening of the oil, and slight bearing and race damage. All seals and bearings were replaced by Aerzen, and a bleed apparatus was installed to equalize pressure from the shaft side grease port. At the end of the tenth test, oil had leaked out of the pressure relief system valve that was unintentionally left open prior to the start of this test. No significant conclusions were determined from this test. For the eleventh long duration test, oil had been found on all surfaces of the blower and pressure vessel interior. The origin was never determined, although speculated that oil had blown through the plumbing from oil leaks in previous tests. Two GoPro cameras were placed in the vessel to determine the origin of the oil leak during 40 minutes of blower operation. Fortunately, there was no significant oil leak during this short test. However, the twelfth test proved that there was still a source for oil leaks originating from the blower or pressure relief apparatus. The location of the oil leak is still unknown. Overall, these were very successful longduration tests, and important operational items continue to be learned.

\section{Future Studies}

A high pressure (deep sea) video camera has been purchased in order to further investigate the blower oil leaks. The video camera will allow us to record live video of the blower during normal operation and without interruption. The video camera and recording hardware will be installed for the next long duration test. 